\title{
The Role of Silence at the Retreats of a Buddhist Community
}

\author{
KOME - An International Journal of Pure \\ Communication Inquiry \\ Volume 4 Issue 2, p. 59-73. \\ (C) The Author(s) 2016 \\ Reprints and Permission: \\ kome@komejournal.com \\ Published by the Hungarian Communication \\ Studies Association \\ DOI: 10.17646/KOME.2016.25
}

\section{Orsolya Huszár}

Corvinus University of Budapest, Institute of Behavioural Sciences and Communication Theory, Doctoral School of Social Communication, Hungary

\begin{abstract}
The purpose of the study is to establish that the definition of silence as simply an absence of something or as the background of communication proves to be inadequate in a number of communicative instances. The interpretation of silence is culturally determined, and the underappreciation of its role is typical in low-context Western cultures; this is also evinced by the neglect of the topic in the literature. The present study will describe the communicative functions of silence through the findings of field work conducted at the retreats of a Buddhist community in Hungary, providing empirical input for the relevant theoretical constructs. The research findings show that silence is accorded a central role in essentially every component of the retreat (meditations, relaxation, ceremonies, teachings, small-group sharings, meals and rest); and while each event at the retreat focuses primarily on a different specific function of communication, the entire retreat does involve the linkage, affecting, revelational and - to a certain extent activating functions (to follow the five-element typology of J. Vernon Jensen), as well as - to a lesser extent - the judgmental function. The research also shows that it requires time for individuals in a low-context culture to recognize the "point" of silence something that the retreats provide the right opportunity for. In fact, the insights the individuals arrived at through these occasions could be put to use in their daily lives, helping their problem-solving and social relationships and in general improving their quality of life.
\end{abstract}

Keywords: silence, communicative functions, high- and low-context cultures, Buddhism, retreats 


\section{Theoretical Background - The Underappreciated Nature and Communicative Functions of Silence}

Anyone seeking books or studies about silence will encounter several such pieces of writing, with the majority of them examining the subject in a religious or linguistic context. Certainly, the discussion of the religious context will surprise no one who has ever participated in a religious ceremony or gathering - or has even read about such events anywhere, including in news reports. The linguistic approach is similarly unsurprising. But if one wishes to read specifically about the communicative function of silence, the discussion of this aspect of silence is inadequate and fails to go into sufficient depth. Nonetheless, studies and book chapters have been published in English on the subject; these appear either in works dealing with the theory of communication or deal with silence as it pertains to their specific area of study (business communication, the communication between a doctor and their patient, etc.). At the same time, very few extensive publications have examined silence specifically - Adam Jaworski's book entitled The Power of Silence: Social and Pragmatic Perspectives is one such example, along with Silence: Interdisciplinary Perspectives, also edited by him, as well as the book entitled Perspectives on Silence edited by Deborah Tannen and Muriel Saville-Troike. The strength of all three books lies in their interdisciplinary and intercultural approach, their significant use of the literature, as well as the inclusion of various areas (education, politics, the arts, everyday communication and ritualistic communication, gender roles, etc.) in their analysis. This discussion of a broad range of communication phenomena, on the one hand, makes possible the recognition that defining silence as simply an absence of speech (or noise or sound) proves to be inadequate in the majority of cases and represents an unnecessary simplification, and on the other hand, situational and intercultural comparison makes it possible to more easily analyze the various - highly culture-specific - meanings and functions of silence in various situations. This article endeavors to contribute to this discussion - and while the point of departure here is also a (quasi-)religious context, we ultimately arrive at applications in communicative situations in everyday life.

Defining silence as simply an absence of something or a background of communication is an approach that is oftentimes proved incorrect even in informal, everyday conversations; this holds true, however, especially in instances of communication such as a court hearing, a business negotiation, a police interrogation, the exchange between a student and a teacher in a classroom, a political speech or some religious practice. Silence, in these situations, often carries a special meaning or function, regardless of whether or not it is used consciously by the parties communicating. The fact that silence nonetheless remains "underappreciated" in the literature may be due in part to the typically Western approach connected with it, which suggests that speech is the norm, and silence represents a departure from the norm. Ron Scollon, for instance, in The machine stops: silence in the metaphor of malfunction, criticizes this attitude, claiming that in modern, industrialized society (including mainstream American society), humans are conceptualized in a metaphorical sense as machines; and because in the case of a machine it is a constant hum that indicates that all is working properly, in the case of humans, it is speech which is the same kind of indicator. "Smooth talk is taken as the natural state of the smoothly running cognitive and interactional [human] machine" (Scollon 1985: 26). Jaworski, on the other hand, suggests this represents a somewhat oversimplified approach, because even Western cultures tolerate a certain - culturally variable - degree of silence, even if it is perceived more negatively than speech (Jaworski 1993). In general, however, it may be concluded that in mainstream Western cultures, a faster pace of speech, shorter pauses and more frequent turn-taking in conversations are seen more positively than a slower pace, longer pauses and lengthier comments. 
If we accept, hypothetically, that silence also possesses a communicative function, it is worth referencing Vernon Jensen's typology. He differentiates among five communicative functions of silence, attaching positive and negative values to each. These functions are the following:

1. A linkage function: silence can bind together people and deepen their relationship; it can also sever relationships. It is also possible to use silence to purposely isolate ourselves from others, protecting ourselves by a wall of silence. Silence, however, can also build community, just as speech also is able to both build and destroy a community. Silence can forge bonds between husband and wife and among friends; it can serve remembrance; and for religiously oriented individuals silence is frequently the specific vehicle for linking them to God.

2. An affecting function: silence affects us; it can heal and it can wound. In difficult moments silence can be an important tool to prevent aggravating the situation; in other cases, silence may cut more deeply than speech. Silence can communicate understanding, respect, acceptance, kindness - as well as indifference, animosity, coolness, defensiveness and ruthlessness.

3. A revelational function: silence can facilitate understanding, but it can also hide information. It can suggest that one of the parties communicating is not in possession of the necessary knowledge. Psychotherapists often learn more about their patient by their silence than through the information they provide. Silence can actually reveal things - for instance about ourselves and our "true" inner being. For that reason, many are afraid of silence and are afraid of being left alone with their thoughts and feelings.

4. A judgmental function: silence can indicate assent or support, but it can also be employed to register disagreement. Silence on the part of the auditor frequently suggests agreement, but at the same time, in the case of obvious injustice, silence can mean the opposite - disagreement, hostility or anger.

5. An activating function: silence can refer to both deep thoughtfulness as well as an absence of mental activity. A public speaker who pauses for a moment may give the impression of thoughtfulness - we often assume, in fact, that the silent person is engaged in thought while the talking person is not. At the same time, we also believe that remaining silent without performing some kind of physical activity means that the individual is not doing anything meaningful (Jensen 1973).

Subsequently in the study, I will attempt to demonstrate how these functions appear at a Buddhist retreat. Before, however, it is necessary to take a look at the cultural determinism of interpretations, while at the same time providing additional considerations for the positive and negative meanings described in Jensen's typology of silence.

\section{Theoretical Background - Cultural Determinism}

Different ways of managing speech and silence can easily lead to intercultural misunderstandings. "For a stranger entering an alien society, a knowledge of when not to speak may be as basic to the production of culturally acceptable behavior as a knowledge of what to say." (Basso 1972, as cited in Enninger 1991: 8). It is not enough, however, to learn what to say and when to say it in a given culture: one must also learn to interpret silence appropriately. In many cases, this is far more difficult than interpreting spoken words - it begins by having to recognize whether or not the silence in that particular situation even carries any unique 
meaning, or if it is simply a pause - without meaning - in the conversation. In addition to an intercultural comparison of the various cultures, small communities with unique cultures existing within the majority society may provide a suitable venue for investigating this; often, these smaller communities are in fact religious communities. Examples of these include Amish communities in the United States and Canada (see, for example, Enninger 1991) or the Quakers of Great Britain.

A study by Sandra Bell and Peter Collins, examining the Quakers of Great Britain and Theravāda Buddhists (Bell and Collins 2014), provides an excellent example of intercultural comparisons related to the communicative function of silence. In the study, the authors link silence to stillness and to non-activity as a means of evoking a sacred presence; they emphasize the aesthetic and ethical value, and the ontological and moral significance of silence as far as these communities are concerned. According to Bell and Collins, neglecting to examine silence substantially hinders not only the understanding of these specific communities, but also the understanding of religious communities in general: even though their cultural contexts may be different, silence - in the form of prayer, worship, meditation and contemplation - is clearly linked to the ineffable. Silence, here, represents a state of receptivity to religious truths that lies beyond conditioned reality which is only partially accessible through words. Silence and the state of repose associated with it create ideal conditions for spiritual attainment (Bell and Collins 2014). Because the observations of Bell and Collins among British Theravāda Buddhists are closely in line with my own observations, I will be returning to their conclusions tangentially later.

In order to understand the culturally determined role and functions of silence, the distinction between high- and low-context cultures (the concept is associated with Edward T. Hall) provides a useful point of departure. In high-context cultures, as a result of closer human relationships and due to more broadly shared social and cultural knowledge, verbal communication plays a lesser role; at the same time, members are expected to decode precisely nonverbal acts of communication. In these cultures, communication serves more to establish contact than to relay information. In low-context cultures, on the other hand, verbality plays a more prominent role, and communication is aimed primarily at transmitting information. The theory of cultural value orientations by Florence Kluckhohn and Fred Strodtbeck places cultures in a matrix where low-context cultures are characterized, with respect to the "activity" orientation, ${ }^{1}$ as "doing"-oriented. Mixed cultures are characterized by "becoming," and highcontext cultures by "being." As far as the perception of silence is concerned, there is a distinction between "doing" and "being-in-becoming" cultures: "...persons from identifiably doing-oriented societies tend to regard silence as an absence of words, a waste of time, a period when »nothing is doing «. For those who can be characterized as of the being or being-inbecoming mode, silence in conversations has positive meaning: It is essential to self-fulfillment and to an awareness of here and now" (Condon and Yousef 1975: 137, as cited in Enninger 1991: 13).

When an individual belonging to a low-context culture (a culture of "doing") has to integrate into a high-context cultural (a culture of "being") setting, and has to adapt to its rules, a different

\footnotetext{
${ }^{1}$ According to Kluckhohn and Strodtbeck, humankind is faced with five major problems that are common to all and that all societies have sought answers to at all times: "How a group is predisposed to understand, give meaning to, and solve these common problems is an outward manifestation of its innermost values, its window on the world: its value orientation." These problems are summed up in the questions below:

"- What is the temporal focus of life? (Time orientation)

- What is the modality of human activity? (Activity orientation)

- What is the modality of a person's relationship to others in the group? (Relations orientation)

- What is the relationship of people to nature? (Person-nature orientation)

- What is the character of innate human nature? (Human nature orientation)" (Gallagher [2001])

High-context, mixed and low-context cultures provide different answers to these questions.
} 
management of time and activities, and the consequences of this, may present difficulties to them - for instance, their propensity to follow rules may decrease as a result of boredom and impatience (in the case of communication and in general in terms of rules of behavior). At the same time, the situation is somewhat different when a person has to adapt individually to new and different expectations and rules in a foreign cultural setting, than when an entire community has to do the same in their own surroundings. An example of the latter occurrence is when a community following an Eastern religion or philosophy is established within a Western society.

In North America and Europe, a number of such communities have been established in the last century; the majority of these do not function "purely" but do so in some kind of syncretic and adapted way. This is clearly obvious in the case of Buddhist groups, beginning with the fact that in the West, the Buddhist way has been transferred almost entirely from monasteries to settings of everyday life. Although a number of different forms and schools exist in North America and Europe, these all tend to adapt (because they must adapt in order to subsist) to their local environment (groups which specifically serve the needs of immigrants from the countries of origin must be treated separately and will not be discussed here). Despite this adaptation, Western Buddhist communities must acquire an entirely different system of communicating - one in which silence occupies a central position.

When conducting field work for my dissertation at retreats of a Hungarian Buddhist community, one of the most striking experiences was silence and listening in the community. The novelty of this lay not in the silence itself, but in the communal experiencing of this silence. This was my first experience with a situation when quiet periods were governed by an entirely different set of principles than what I had been used to. In terms of the function and rules of silence and listening, Hungarian society belongs - with certain differences in emphasis among modern Western societies: one must remain silent at certain events, ceremonies, at the movies or in the theater, at school, at presentations, etc. At such times, silence is often of a passive nature: it serves simply to avoid disturbing the event, the presenter or other participants, and it is something that is typically prescribed (explicitly or implicitly) by social rules. Accordingly, Hungarian literature - apart from specifically linguistic discussions - only deals sporadically with the communicative role of silence; the topic is mentioned briefly only in works dealing with general theories of communication. ${ }^{2}$ Thus, an examination of the field offers plenty of opportunity for further discussion.

\section{Theoretical Background - Buddhism}

In recent years and decades, retreats of various types have enjoyed increasing popularity in the Western world. This is clearly the result of the noise around us, and the levels of stimuli and stress affecting each person on a daily basis. As Thich Nhat Hanh, the Zen master of Vietnamese origin living in France, writes in his book entitled Silence: The Power of Quiet in a World Full of Noise:

\footnotetext{
${ }^{2}$ In one Hungarian-language statement, Katalin Kukorelli describes one of her smaller-scale studies conducted among her students. Her motivation for the study was the recognition, during the teaching of one session of her practical subjects, "that a significant number of the students are unable to follow the communication going on and the train of thought of their peers. They are unaccustomed to paying attention to one another and to communicating verbally in one shared space. They are also unaccustomed to decoding hidden messages, noting the way how something is said and not only to listening to what is said. Kukorelli conducted a survey, using questionnaires, among her students, asking them if we are saying anything when we are silent. By her own admission, the single objective of the survey was "to examine whether or not it is worthwhile to study the role and functions of silence and listening in communication." (Kukorelli 2011: 133-4)
} 
Unless you live alone in the mountains without electricity, chances are you're absorbing a constant stream of noise and information all day long, without interruption. Even if no one is speaking to you and you're not listening to the radio or some other sound system, there are billboards, telephone calls, text messages, social media, computer screens, bills, flyers, and many other ways that words and sounds reach us. It sometimes can be impossible to find a corner of an airport boarding area without a television blaring. Many people's morning commute is spent absorbing tweets, texts, news, games, and updates on their phones. Even in those rare moments when there is no sound, text, or other information coming in from outside, our heads are filled with a constant loop of thoughts. How many minutes each day, if any, do you spend in true quiet? (Hanh 2015: 20)

For precisely this reason, those seeking relaxation, quiet recreation, or answers to questions they may have, have been able to choose from among a broad range of retreats. There are Christian and Buddhist retreats, yoga and silent camps, etc.; but we may also mention the various pilgrimages. What is common to all of these is that they provide an opportunity to break free from the routine and noise of everyday life, to deepen one's self-knowledge and to engage in a kind of mental rest. An additional common feature is that they replace verbality with observation and experiencing. The most radical form of this is the kind of silent retreat where both verbal communication as well as nonverbal communication (e.g., looking at one another) are forbidden for the entire duration (up to ten days). In these cases, silence has no discernable communicative function - apart from the individual's internal dialogue with themselves - and it is rather self-knowledge attainable through isolation that is emphasized. In the Buddhist retreats I visited, on the other hand, silence did carry several communicative functions, as will be described below.

In Buddhism, silence and listening traditionally play an important role. Buddha himself chose silence as far as several significant metaphysical and existential questions are concerned, opening up avenues for various interpretations and speculation by doing so. These questions included the following: the world is eternal or not; the world is finite or infinite; the soul is the same as the body or soul is one thing and the body is another; and after death a Tathāgata [historical Buddha himself] exists or does not exist or both of them exist and do not exist (Ñāṇamoli and Bodhi 2001: 533).

According to the teaching, it is only through a quieting of one's mind that one can arrive at true insights; if there is noise (external noise and the noise of one's thoughts), one cannot see the true nature of things. Therefore the main forum for acquiring such insights is quiet meditation. From a historical perspective, however, this did not always occupy such a priority position, for instance, in the Zen school. Steven Heine (2013) writes that during the Tang dynasty, Zen masters were above all else skilled speakers; he quotes text parts which demonstrate that meditation was less important (or was less organized/regulated) than individual, private teachings which motivated students could acquire from the abbot. Heine says that if we examine the role of language in Zen Buddhism, we immediately come across a predicament to be resolved. Because this school emphasizes the transmission of teachings not through sacred texts (i.e., not through words or letters), in Zen temples one would expect to encounter eloquent silence as opposed to teachings conveyed through the spoken word perhaps soft murmurs, the rustling of leaves, etc. (which are considered to evoke the voice of Buddha), non-verbal noises made by the monks (the sounds of them going about their daily lives), the sound of the bell, recitation and the chanting of Sütras (and perhaps explanations attached to them). At the same time, historical studies suggest that in Zen - through verse and prose, for instance, through the explanations of the kōans - verbal communication has always played an important role. Heine therefore asks whether this discrepancy - emphasizing language use while at the same time oppressing its transcendence - can be ascribed to a fundamental contradiction in the tradition, or if it means that we must reconsider just how exact 
our knowledge is of what constitutes Zen transmission as far as rhetorical discourse is concerned. According to Heine, we may believe that mystics are violating their sacred principles; or we may conclude that the role of language in Zen - by incorporating several texts which serve the religious practice of liberating the mind from fixation and attachment - would be to find the middle path between ineffability that abandons words and the view that verbal expression and speech play a central role in the quest for enlightenment. In this sense, Zen is known primarily not so much for denying speech (which is an extreme viewpoint), but for inventing a creative, new style of linguistic expression, and for its unusual and novel use of the language as manifested in the kōans. Additionally, Zen has always emphasized silence, although there has always been a debate over whether it is to be considered the goal that language serves as a means to attain, or just the opposite, whether silence is the means and creative language use is the goal (Heine 2013).

I will not go into the various positions related to this question here, as the subject would digress from the present study; but if we look to the Pāli texts for guidance, we see that silence is valuable for Buddhism in itself, as, for instance, the passage below from the Sandaka Sūtra shows:
Now on that occasion the wanderer Sandaka was seated with a large assembly of wanderers who were making an uproar, loudly and noisily talking many kinds of pointless talk, such as talk of kings, robbers, ministers, armies, dangers, battles, food, drink, clothing, beds, garlands, perfumes, relatives, vehicles, villages, towns, cities, countries, women, heroes, streets, wells, the dead, trifles, the origin of the world, the origin of the sea, whether things are so or are not so. Then the wanderer Sandaka saw the venerable Ānanda coming in the distance. Seeing him, he quieted his own assembly thus: 'Sirs, be quiet; sirs, make no noise. Here comes the recluse Ânanda, a disciple of the recluse Gotama, one of the recluse Gotama's disciples staying in Kosambī. These venerable ones like quiet; they are disciplined in quiet; they commend quiet. Perhaps if he finds our assembly a quiet one, he will think to join us.' Then the wanderers became silent. (Ñānamoli and Bodhi 2001: 618)

Thus, in Buddhism, silence is a quality per se: in Pāli canonical texts, the term appasaddakāma is often used to describe Buddha and his followers, meaning "lovers of quietness." This also featured in the teachings of Thich Nhat Hanh.

\section{Thich Nhat Hanh's Western Buddhism and Noble Silence at the Retreats}

Engaged Buddhism, the Western Buddhism represented by Thich Nhat Hanh, relies on the various schools of Buddhism, being primarily based on Vietnamese Zen (thiền) and Theravāda traditions. Teachings are formulated in a way so as to make them applicable for Western individuals in their daily lives, relying on everyday situations. Thich Nhat Hanh deals with internal transformation, whose aim is to better the individual and society - this includes both monks' "traditional" contemplation in a monastery as well as the active representation of important social questions (rejection of violence, forgiveness and helping the suffering). He has written over one hundred books which lay out his teachings in simple language that is easy to understand and focuses on practice. In Plum Village, his community of monks, retreats organized for lay participants - follow the same general direction, extending meditation to the most routine, everyday tasks (turning washing the dishes or gardening, etc. into opportunities for meditation). Participants of the retreats in France (held in English and French) come from various countries. The field work serving as the foundations for the present study was conducted at the retreats of a Hungarian community following the spirit of the teachings of Thich Nhat Hanh, held in English (with Hungarian interpretation) by Dutch and Vietnamese 
teachers from the Netherlands. The schedules of the longer (six-day-long) retreats held in Hungary largely match those of the retreats in Plum Village. ${ }^{3}$

Seeking the middle way, mentioned above, and emphasizing that followers should refrain from meaningless chatter, is also a feature of Thich Nhat Hanh's teachings. The more verbal program elements of the retreats also support this more reserved approach. Because, according to the teachings, the usual activities in one's everyday life may also serve as occasions for meditation (which receives special emphasis in Western Buddhism, and more closely matches the Western lifestyle), what is important at such occasions is for the practicing Buddhist to perform the given activities with mindfulness, focusing on the task at hand. This is also supported by silence, especially in the case of beginners. Thich Nhat Hanh describes the relationship between silence and mindfulness in the following way:

For those who are just beginning to practice, it is best to maintain a spirit of silence throughout the day. That doesn't mean that on the day of mindfulness, you shouldn't speak at all. You can talk, you can even go ahead and sing, but if you talk or sing, do it in complete mindfulness of what you are saying or singing, and keep talking and singing to a minimum. Naturally, it is possible to sing and practice mindfulness at the same time, just as long as one is conscious of the fact that one is singing and aware of what one is singing. But be warned that it is much easier, when singing or talking, to stray from mindfulness if your meditation strength is still weak. (Hanh 1987: 29)

In other words, the point of the retreat for followers of Thich Nhat Hanh is not for participants to remain completely silent. Silence here represents - in addition to being, as we have seen, a quality per se for Buddhists - the means to quieting the mind, to acquiring insights and to coming to understand the true nature of things (and of oneself).

If we consider it to be a means to acquiring insights, in this fundamental function, silence does not necessarily appear to be communicative in nature (although we may detect what Jensen refers to as the revelational function) - but it is clear that it cannot be defined as simply an absence (the absence of speech or noise). From an epistemological perspective, it carries special significance: listening is a method of acquiring understanding. Szczypiorski mentions an example which highlights that silence - embedded in its epistemological function- may be considered a unique communicative experience. The elements of this example closely resemble the experiences the individual may encounter during meditation (in fact, the experience described may be considered an actual instance of meditation):

Today, during the walk, when I was pretty exhausted, I sat down on the hammock of an easy hill and leaned against a pine trunk. There was some huge silence around. No breeze, no rustling of the branches, no bird. Silence and nothing else. This was very nice. But, unfortunately there was also myself. And after a while unusual shouting rose in myself. This shouting probably swirls always, but I don't hear it because I'm very busy with many everyday activities, reading, or simply walking. And in silence which fell when I sat down, I suddenly heard all of my inner voices, chattering and furious, as if they were finally able to shout out to me all the latent themes. ... Very stupid questions. What next? Why did it happen? What is the way out of this? What should be done? What did I need that for? And there is only one answer all the time: I don't know. (Szczypiorski 1989, as cited in Jaworski 1993: 19)

Buddhist retreats, however, involve not just silence as such, but "noble silence." If we look to investigate the roots of noble silence, it is worthwhile to turn to the texts of the Palli canon: (Samyutta Nikāya - the third major collection in the Sutta Pițaka). In the text entitled

\footnotetext{
${ }^{3}$ http://plumvillage.org/retreats/visiting-us/sample-schedule/
} 
Bhikkhusaṃyutta (Connected Discourses with Bhikkhus), Mahāmoggallāna contemplates noble silence:

\begin{abstract}
"Here, friends, while I was alone in seclusion, a reflection arose in my mind thus: 'It is said, "noble silence, noble silence." What now is noble silence?'

"Then, friends, it occurred to me: 'Here, with the subsiding of thought and examination, a bhikkhu enters and dwells in the second jhāna, which has internal confidence and unification of mind, is without thought and examination, and has rapture and happiness born of concentration. This is called noble silence.'

"Then, friends, with the subsiding of thought and examination, I entered and dwelt in the second jhāna, which ... has rapture and happiness born of concentration. While I dwelt therein, perception and attention accompanied by thought assailed me.

"Then, friends, the Blessed One came to me by means of spiritual power and said this: 'Moggallāna, Moggallāna, do not be negligent regarding noble silence, brahmin. Steady your mind in noble silence, unify your mind in noble silence, concentrate your mind in noble silence.' Then, friends, on a later occasion, with the subsiding of thought and examination, I entered and dwelt in the second jhāna, which has internal confidence and unification of mind, is without thought and examination, and has rapture and happiness born of concentration.

"If, friends, one speaking rightly could say of anyone: 'He is a disciple who attained to greatness of direct knowledge with the assistance of the Teacher,' it is of me that one could rightly say this." (Bodhi 2000: 713-4)
\end{abstract}

The disciple then is dwelling in the second jhäna here, in a deeply euphoric state where the stream of thoughts comes to a standstill. They are able to reach this state of joy through concentration (samādhi). Through concentration, we are able to obtain answers to questions such as the following: Who am I? What do we want to do with our life? Why are we here? Who are we, each of us individually? What do we want to do with our life? Thich Nhat Hanh emphasizes that these are not simply philosophical questions, but questions which must be answered for a person to find joy and peace in their life. And if we have enough time and concentration, we may find some surprising answers. Concentration requires silence in order for us to break free of the stream of our thoughts and to hear the call of our hearts (Hanh, 2015: 13-4).

To an outside observer, it is difficult to distinguish between silence during meditation and simply refraining from speaking; participants, however, understand the difference. When someone begins meditating, their first recognition generally pertains to the constant nature of internal dialogue - this is why meditation is aimed precisely at silencing it. In group meditation, each meditating member does so in their own silence; my research has shown, however, that for many (but not for everyone), group meditation offers qualitatively different experiences than individual meditation. Reinforcing and supporting by the community, and experiencing silence together, are important for them. (Bell and Collins make a similar statement regarding the British Theravāda Buddhists in their study quoted already.) In these cases, group meditation carries a connecting function, and it is aimed at ending the individual's isolation (in addition to making it easier to practice). For people belonging to low-context cultures, this connecting communicative function of meditation is exposed only over time, through experience. Several of the individuals I spoke with during my field work described how strange it was initially to have a group of people sitting together in silence in the same room. "It was as though we were doing nothing" (see Jensen, above, on the activating function).

To an outside observer, walking meditation, which is also done in silence, may appear to be similarly peculiar. At first glance, these may appear to be events where individuals not communicating with one another are walking somewhere at a very slow pace. This kind of meditation is different from sitting meditation in that it is directed more externally, more 
towards the outside world. It provides an opportunity to connect with members of the organic world, and to meditate about their true nature. ("Breathing and walking in mindfulness puts us in touch with the miracles of life all around us, and our compulsive thinking will dissipate very naturally" [Hanh 2015: 59]). It remains true for this kind of meditation that practicing it in a group setting may provide a different experience than a solitary walk. Experiencing silence together helps the individual connect with another. At the same time, walking meditation is a simple way of quieting the mind without setting the quieting of the mind as our specific goal. The individual meditating while walking is always focusing on their next step and (similarly to seated meditation) on breathing, resulting in joy, consciousness and ultimately in the selfhealing of body and mind:

In that short amount of time you can experience the bliss, the joy, the happiness of stopping. During that time of stopping, your body is able to heal itself. Your mind also has the capacity to heal itself. There is nothing and no one to prevent you from continuing the joy you've produced with a second step, a second breath. Your steps and your breath are always there to help you heal yourself. (Hanh 2015: 58)

Retreats, however, are about more than just activities defined specifically as meditation. Meditation is actually a key part of the ceremonies, including of ceremonial meals. Although the majority of the participants of retreats I visited did not identify themselves as religious, and do not interpret Buddhism as a religion, the ceremonies of a retreat are, by definition, religious events, where on the one hand participants pay respect in various ways (to Buddha, the bodhisattvas, ancestors of the participants and to the living creatures of the Earth) and on the other hand certain ceremonies (such as the Three Earth Touchings ${ }^{4}$ ) serve to restore the broken bonds between living creatures. (If we approach it from the perspective of cultural context, this ceremony involves a ritual form of the communicative function aimed at connecting that is typical of high-context cultures.) Silent meditation is always a part of these ceremonies: the meditation performed at the beginning of the ceremony prepares the individual for their full participation in the ceremony and for focusing on the ceremony. In the case of meals - which are introduced by the giving of thanks and then proceed in silence - silence serves to help make the individual partaking in the meal internally aware of the sacrifice and work that produced the food on their plate (thereby reinforcing their connection to the living creatures of the world); and through this conscious recognition, the individual may change their negative dietary habits, such as gluttony. In these cases, then, it would once again be difficult to consider silence as simply an absence of speech. The introductory silent meditation is an important part of the ceremony; if we wish to describe these as complex communicative events, we cannot bypass defining the function of silence. Certainly, this holds true not only in the case of Buddhist ceremonies, as various religious practices feature separate episodes of silence and noise, each with their own meaning. These meanings are, however, culturally defined, and the "silences" are also not identical: one may make a distinction between, for instance, internally motivated silence and silence stemming from social rules (these may also converge, as for example in the case of meditation). And, as Jaworski points out: „the quality and quantity of silence are subject to change, but what is also very important, the qualitative, and to some degree the quantitative, changes of silence depend on the subjective perception of the individual. Thus what may seem as an absolute and undifferentiated span of silence to one person (the observer) may consist of various, however subtle and inexpressible, silences charged with different overtones and meanings for another (the participant)" (Jaworski 1993: 43). And while silence itself is unspeakable, the experiences one acquires during a period of silence - at least on a certain level - may be communicated, as is sometimes done within communities.

\footnotetext{
${ }^{4} \mathrm{http} / /$ plumvillage.org/key-practice-texts/the-three-earth-touchings/
} 
To what extent is the silence at the retreat something that comes from within, and to what extent does it stem from "social" rules? We may conclude that the community has its own rules for silent periods, but these rules generally match the needs of those participating in the retreat. Additionally, interviews with members of the community (as well as my own personal observations) have shown that individuals undergo significant change during their first retreat as far as their tolerance for silence is concerned. Initially, many of them found the silence to be strange, but within a couple of days, their initial reservations were replaced with an enjoyment of the silence. When asked the question, "How do you benefit from a retreat?" respondents typically said, "I benefit by experiencing silence, being present in the present and feeling happiness." The dynamics of daily life change in a silent environment, and participants find ways to connect with one another through means other than verbal communication. The field work also made it clear that silence actually represents an important attraction. In addition to the aforementioned benefits, it also serves to "equalize," in a way: it dampens the voice of opinion leaders and makes the setting more comfortable for more introverted individuals, who do not feel they are expected to "chit-chat" - two elements which are otherwise typical of a verbal environment. Furthermore, opinion-leader-type individuals (or persons who hold leadership positions in their fields) are also attracted by this opportunity to step outside their usual roles and remain in the background. Certainly, these effects cannot be ascribed exclusively to silence, but I believe silence does play an important role.

The dynamics at a retreat differ greatly from the dynamics of everyday life. This is facilitated, in addition to the periods of silence already described, by periods of night-time noble silence, which starts after the last activity of the evening (meditation or a ceremony) and goes until the end of breakfast the following morning. The function of silence during these periods is not only relaxation, but also to make rest possible for other participants. Thus, silence is the framework which helps others rest, and thereby helps the individual respect others (affecting function). Cultural determinism is quite apparent here - maintaining noble silence is something that is difficult for many (at night and during meals); this is due not to disrespect or an intentional disobeying of rules, but stems typically from everyday habits. Retreats, however, have their own dynamics in this respect: as the days go by, it becomes easier to abide by this rule. The reason for this, for instance in the case of those attending their first retreat, is that the "point" of maintaining silence is gradually made clear to participants. The passage below provides a short and very simple summary of this rule and its underlying rationale:

The practice is easy. If we are talking, we are talking. But if we are doing something else - such as eating, walking, or working - then we do just these things. We aren't doing these things and also talking. So we do these things in joyful noble silence. In this way, we are free to hear the deepest call of our hearts. (Hanh 2015: 6)

In terms of differences compared to communicative habits of low-context cultures, however, the way small-group conversations (so-called family sharings ${ }^{5}$ ) are conducted is perhaps the most interesting. Apart from the fact that these conversations, too, typically begin with sitting in silence for several minutes, turn-passing and turn-taking are different, and in a way they are more regulated, but in other ways they take place in a manner that is more liberal. They are more regulated because one is expected to indicate their intention to speak by taking a slight bow (with hands in the lotus position), just as they are expected to do the same to signal that they have finished speaking. Cutting off the other is not permitted; there is no penalty for doing so: the discomfort the individual would feel in such an instance for breaking the rules proves

\footnotetext{
${ }^{5}$ At the beginning of the retreat, participants are assigned to smaller groups - "families" -; participants then spend certain activities of the retreat (meals, joyful work, sharings) in their own family. Each family has a head, who is generally someone who has belonged to the community for a longer time.
} 
sufficient (occasionally, the "family elder" may also offer a gentle warning). On the other hand, it is also more liberal, because there is no expectation to respond to what anyone else said, and everyone can speak their mind regardless of the comments of the person speaking before them. It is, however, not allowed to qualify the comments of the person speaking before. In these cases, remaining silent serves to show respect to the other person and for the fact that they have opened up, as well as acceptance for their experiences, for their interpretations and of their conclusions (judgmental function). These sessions, of course, have themes: they are generally related to the teachings that day, but do not play out as debates or dialogue; they rather provide a forum for sharing individual observations, feelings, impressions and conclusions. On the whole, they facilitate learning to listen attentively, understanding the position of the other person, accepting the unique validity of their viewpoints, and placing greater emphasis on the emotional dimension over the functioning of the discursive mind. Thus, changing the "rules" of communication in this way makes it possible to, and facilitates, changing one's perspective, which is also manifested in the fact that the silence is often accompanied by nonverbal communicative acts of encouragement, support and compassion. We must, however, mention as far as the negative aspect (linkage function) is concerned that these rules also make it possible for the individual to wrap themselves in silence and to maintain their isolation - this is, however, often resolved over time during the retreat.

The interviews showed that all of the opportunities at experiencing laid out above have the potential to make deep enough impressions on participants that they would be able to actively apply the skills and insights acquired through them later in their personal lives and in their work. Especially in the case of individuals working in leadership positions, this may also result in them taking specific steps in their workplaces to change their established communicative and problem-solving habits. Interview subjects highlighted an improvement in their teamwork, a termination of unhelpful workplace competition, an increase in compassion and satisfaction and more sincere communication. Although the study, confined to one single community (albeit with different individuals and with varying numbers of participants), was not representative, the results were still fairly unequivocal, indicating it may be worthwhile to examine these questions in the case of other communities.

If we want to shed more light on just how retreat participants reached these results, we may turn to Nyanaponika Thera, the Sri-Lankan Theravāda monk, who specifically emphasized that for lay individuals, it is vipassana (bare attention) meditation which is most appropriate; this approach is also sometimes referred to as insight meditation. Bare attention uncovers the variability and passing nature of things, as well as the false concept of self. Through seated meditation about dependent existence, we obtain insight: "by the simple device of slowing down, pausing and keeping still for bare attention, all three of the characteristics of existence - impermanence, suffering, and non-self - will open themselves to penetrative insight (vipassana)" (Nyanaponika 2001: 35). And insight involves a kind of knowledge, competency and confidence which results in better communication. "Insight is a means of self-transformation, making the meditator more receptive and sensitive to fellow human and other beings, and hence skilful (Pāli - kusala) in his dealings. Silence and stillness are therefore endowed with moral value" - according to Bell and Collins (2014: 12).

Thich Nhat Hanh says it requires silence for us to be able to return to ourselves. Because we are generally afraid of being alone with ourselves and our anxieties, we turn to various stimuli to hide our suffering. And if we do so - turn to such stimuli - temporarily, for instance during a difficult time in our lives, to help hide our suffering, then that can become an addiction. Stimuli in our surroundings have an effect on us: for instance, if we are surrounded by angry persons, then we ourselves become angry. Humans have four kinds of nourishment: edible food, sense impressions, volition and consciousness (both individual and collective). Conversations may be considered sense impressions, meaning also that during a conversation, 
we take over our partner's energies. This may mean that at the end of a conversation, we feel worse, and not better. During silent meditation, we may make ourselves conscious of these things: of the reasons and manifest forms of our fears and anxieties; and through the insight acquired, we may be able to reduce the consumption of such harmful things, leading us to be happier. Insight and happiness - which includes being satisfied with one's own life - helps us relate to others; in other words, it advances empathy, attention and kindness in speech, thereby improving communication. Better communication, in turn, involves avoiding lies and gossip; listening to the other person and considering their perspective; kindness in words; and striving for consensus and resolutions (Hanh 2015).

\section{Conclusion}

The present study has examined the subject of silence. The point of departure for the study was that silence is undervalued in Western societies, a notion that is also reflected by its neglect in the literature. Nonetheless, there exist certain theoretical constructs which can well be used to examine the subject. For such a study, it is worthwhile to utilize the tool of intercultural comparison, as it helps reveal the various approaches to and perspectives on silence. Therefore, in addition to theoretical constructs derived from Western literature, we have also included the approach to silence of Buddhism, based in part on canonical texts and in part on contemporary writings. The results of the field work conducted for the present study have shown that, while a new environment whose rules pertaining to silence are different poses a difficulty for the Western individual, there is a demonstrated need for breaking away from noise, and that the majority of individuals, after a short period of time, are able to adapt to this situation, even if imperfectly. As we have seen, while retreats do not take place in complete silence, the entire retreat is generally characterized by a reserved approach to verbal communication. This reserved approach is not only quantitative, but also qualitative as well, and silence has several functions. In addition to the epistemological theory appropriate to Buddhism (or it is perhaps more precise to say as a part thereof), it is also aimed at changing communicative habits and, as a result, at improving the quality of human relationships and increasing one's awareness of the environment and living creatures. In terms of the communicative function of silence, activities at the retreat involve all five categories laid out by J. Vernon Jensen: the linkage, affecting, revelational, judgmental and activating functions. In the case of various silences experienced at the retreats, it is generally the more positive values which are present, although activities are of course not free of negative aspects either: for some, connecting with others may be difficult, and in their cases, silence may serve as a line of defense to help them maintain their isolation (linkage function); silence may also be a tool to express disagreement (judgmental function). It may also happen that someone is unable to identify with the perspective of the community, or the pace which is far slower than what they are used to in their everyday lives, to such an extent that they do not wish to attend activities of the community again (although the positive aspects of the activating and revelational functions of silence may nonetheless become apparent to them). At the same time, based on the interviews and on my observations, it is my opinion that for participants, it was generally the positive aspect of the communicative functions of silence that was made apparent. If we are looking to categorize the various events from this perspective, it is the judgmental function of silence that appears in family sharings and in informal dialogue; the positive values of the other four functions are present throughout the entire retreat (noting that the activating function is most clearly present at meditations and in relaxation, which in a certain sense may be considered similar). In the interviews, participants most frequently emphasized their experiences connected with the linkage, affecting and revelational functions. 
Because the field work was performed at a Hungarian community following the teachings of Thich Nhat Hanh, it is also worth summarizing how these functions are linked to Thich Nhat Hanh's teachings. I believe the experiences of participants are in harmony with the teachings and with Jensen's categorization. The following very brief passage also references all of the functions mentioned by Jensen: "If we want to be more connected to others, we don't need to text them more; we need to listen to them more. Deep listening leads to understanding. Understanding leads to greater connection. The way to listen more deeply is not simply to try harder. Rather, it is to take time in practice that starts with silence - that is, with quieting our internal Radio Non-Stop Thinking" (Hanh 2015: 168). Practice thus begins with silence: this creates the mental state for gaining insight and understanding (activating function); additionally, as we have already seen in the description of walking meditation, slowing down in silence and concentrating on breathing instead of on speaking in itself carries the power of healing for the mind and body (affecting function). The appropriate mental state and silent concentration make understanding possible - above all, the understanding of ourselves (revelational function). This is necessary in order to develop our relationship to others: empathy, paying attention, speaking style and, ultimately, communication. And better communication results in better human relationships (linkage function), helps problem solving and conflict management (judgmental function) and in general leads to greater satisfaction. As far as communicative functions are concerned, the Buddhist retreat examined may thus well be described using these categories.

\section{References}

Basso, K. H. (1972). To give up on words: Silence in Western Apache culture. In P. P. Giglioli (ed.): Language and Social Context. Harmondsworth: Penguin. pp. 67-86.

Bell, S. and Collins, P. (2014). Religious Silence: British Quakerism and British Buddhism Compared. Quaker Studies: 3(1), 1-26. Available at: http://digitalcommons.georgefox.edu/quakerstudies/vol3/iss1/1

Bodhi, B. (transl.) (2000). The Connected Discourses of the Buddha. Oxford: The Pali Text Society.

Condon, C. and Yousef, F. (1975). An Introduction to Intercultural Communication. Indianapolis: Bobbs-Merrill.

Enninger, W. (1991). Focus on silences across cultures. Paper from the International Conference on Cross-Cultural Communication, March 23-29, 1989, San Antonio.

Gallagher, T. (2001). Understanding Other Cultures: The Value Orientations Method. Paper from the Association of Leadership Educators Conference, Minneapolis, MN, July 2001.

Hanh, T. N. (1987). The Miracle of Mindfulness. An Introduction to the Practice of Meditation. Beacon Press.

Hanh, T. N. (2015). Silence: The Power of Quiet in a World Full of Noise. HarperCollins. Kindle Edition.

Heine, S. (2013). On the Value of Speaking and Not Speaking: Philosophy of Language in Zen Buddhism. In Steven M. Emmanuel (ed.): A Companion to Buddhist Philosophy. Wiley-Blackwell. pp. 349-65.

Jaworski, A. (1993). The Power of Silence: Social and Pragmatic Perspectives. Sage Publications.

Jaworski, A. (ed.) (1997). Silence: Interdisciplinary Perspectives. Mouton de Gruyter.

Jensen, J. V. (1973). Communicative Functions of Silence. ETC: A Review of General Semantics, 30(3), 249-57. 
Kluckhohn, F. R. and Fred L. Strodtbeck (1961). Variations in Value Orientations. Evanston, IL: Row, Peterson.

Kukorelli, K. (2011). A hallgatás szerepe és funkciói. Az aktív hallgatás mint kommunikációs stratégia. Alkalmazott Nyelvészeti Közlemények. 6(1), 133-84.

Ñāṇamoli, B. and Bhikkhu B. (transl.) (2001). The Middle Length Discourses of the Buddha. Oxford: The Pali Text Society.

Nyanaponika T. (2001). The Power of Mindfulness. Penang: Buddha Dharma Education Association Inc.

Scollon, R. (1985). The machine stops: silence in the metaphor of malfunction. In Tannen, Deborah and Muriel Saville-Troike: Perspectives on Silence. pp. 21-30. Norwood: Ablex Publishing Corporation.

Szczypiorski, A. (1989). Z notatnika stanu wojennego. Poznan: SAWW. 